\title{
ENTERIC VIRAL ZOONOSES: COUNTERACTING THROUGH ONE HEALTH APPROACH
}

\author{
Atul Kumar Verma ${ }^{1}$, Sudipta Bhat ${ }^{1}$, Shubhankar Sircar ${ }^{1}$, Kuldeep Dhama ${ }^{2 *}$ \\ and Yashpal Singh Malik ${ }^{1 *}$ \\ ${ }^{1}$ Division of Biological Standardization, \\ ${ }^{2}$ Division of Pathology, ICAR-Indian Veterinary Research Institute, Izatnagar, Bareilly, 243122, Uttar Pradesh, India
}

Received - December 02, 2017; Revision - January 03, 2018; Accepted - January 29, 2018

Available Online - February 20, 2018

DOI: http://dx.doi.org/10.18006/2018.6(1).42.52

KEYWORDS
Zoonoses
Enteric viral infections
Rotavirus
Astrovirus
Calicivirus
Hepatitis virus
Picobirnavirus
Phyloanalysis

* Corresponding author

E-mail: malikys@ivri.res.in (Y.P.S. Malik); kdhama@rediffmail.com (K. Dhama)

Peer review under responsibility of Journal of Experimental Biology and Agricultural Sciences.

Production and Hosting by Horizon Publisher India [HPI] (http://www.horizonpublisherindia.in/).

All rights reserved.

\begin{abstract}
Zoonotic viruses own a strong capability of transmission from animals to human or vice-versa, making them more resilient to quick modifications in their genetic sequences. This provides the advantage to adapt the new changes for better survival, increasing pathogenicity and even learning ability to jump species barriers. Usually, zoonotic viral infections involve more than one host which make them more serious threat to the surrounding inter-genus species. Zoonotic infection also helps in understanding the evolutionary course adopted by the causative virus. The virus sequence based phyloanalysis has given better methods for comparative evaluation of the viral genomes in the probability of transmissions and diversity. Several animal hosts have been identified as reservoirs and for their potential zoonotic transmission abilities. The early and accurate diagnosis of emerging and re-emerging zoonotic viruses becomes inevitable to restrict and to establish correlation with the spread of these viral infections in different milieus. For the in-depth understanding of the prevailing, emerging/ or re-emerging zoonotic enteric viral infections apposite surveillance programmes would be more meaningful in curbing the virus dispersal. There is a need to gather sound scientific information on these pathogens including their reservoir hosts, immunopathology, and genetic diversity. The implementation of relevant public health
\end{abstract}

All the article published by Journal of Experimental Biology and Agricultural Sciences is licensed under a Creative Commons Attribution-NonCommercial 4.0 International License Based on a work at www.jebas.org.

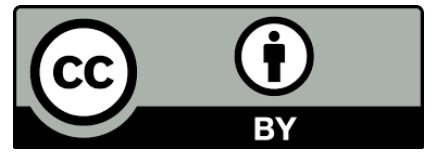


control measures is crucial to reduce disease affliction in a timely manner. Here, we converse the important zoonotic enteric viruses such as rotavirus, astrovirus, calicivirus, hepatitis virus, picobirnavirus, and their variants/types that can take a devastating course, if transmission becomes irrepressible.

\section{Introduction}

Zoonoses are the infectious diseases of animals (usually vertebrates) that naturally transmit to humans via direct contact and indirect routes, and pathogens causing zoonotic diseases pose high public health concerns (Greger, 2007; Tomley \& Shirley, 2009; Wang \& Cremeri, 2014; Klous et al., 2016; Tian \& Tong, 2017). Sometimes human also act as a source of infection for animals in a close contact environmental settings referred as zooanthroponosis (reverse zoonoses) (Messenger et al., 2014). In last two decades, a large number of new infections like Ebola, Zika, Dengue etc., with severe life-threatening and economic consequences have emerged (Singh et al., 2017; Munjal et al., 2017). Under-diagnosis of zoonotic diseases reflects the limited capacity and coverage of health services particularly among poor people. Over the last two decades, the most emerging diseases / pathogens which have been identified are of viral origin viz. Nipah virus, Rift Valley fever, Hendra virus, Pox, Hanta virus, Severe Acute Respiratory Syndrome, Middle East Respiratory Syndrome, Ebola, Zika fever, West Nile virus, Influenza, Rabies, Hepevirus, Japanese Encephalitis, Crimean-Congo hemorrhagic fever, Chikungunya and others (Dhama et al., 2013a; Dhama et al., 2013b; Singh et al., 2017; Munjal et al., 2017). Except for the newly emerging zoonoses such as Ebola, Zika, and highly pathogenic avian influenza $\mathrm{H} 5 \mathrm{~N} 1$, the majority is not prioritized by health systems at national and international levels and are, therefore, being neglected over the time. Gastroenteritis is caused by several infectious pathogens including viruses (Rotavirus, Norovirus, Sapovirus), bacteria (Salmonela, Shigella, Helicobacter etc.) parasites (Giardia, Cryptosporidium, Entamoeba etc.) and fungus (Staphylococcus aureus, Clostridium sp., etc.), and among these all, viruses are the leading cause of acute gastroenteritis. Among enteric pathogens, viruses constitute the major threat as there is a lack of proper therapeutic interventions. The common viral agents responsible for causing enteric infections are Rotavirus, Astrovirus, Picobirnavirus, Norovirus, Sapovirus, Hepatitis E virus, Kobuvirus, Parechovirus, etc. (Dhama et al., 2009; Malik et al., 2014a; Dhama et al., 2015; Sircar et al., 2016).

Severe diarrhoea, vomition and pyrexia indicates for the clinical illness associated with enteric infections, leading to major loss and economic burden across the globe. Along with respiratory tract infections, enteric infections have been pooled in the most common infectious disease syndromes for humans and animals as well and that too in all age groups (Malik \& Matthijnssens, 2014; GBD 2015 Disease and Injury Incidence and Prevalence Collaborators, 2016). Nearly 5 billion diarrhoeic cases occur globally every year and $15-30 \%$ of these severely affected lose their lives, particularly in developing countries with marginal and low income (Tate et al., 2008; Parashar et al., 2009; Malik \& Matthijnssens, 2014). Faecal samples of diarrhoeic cases have been found to be responsible in circulating the enteric viruses, especially certain strains like $\mathrm{G}$ and $\mathrm{P}$ genotypes of rotavirus $\mathrm{A}$ in case of bovines (Prasad et al., 2005; Kusumakar et al., 2010), rotaviruses from avian (Dhama et al., 2015), picobirnaviruses from domestic pigs (Ganesh et al., 2012a). To break the jinx, hand-sanitizers and disinfectants are very helpful in containing certain zoonotic diseases transmitted through unhygienic surroundings, especially where reservoirs are in close contacts (Patnayak et al., 2008). The host's immunomodulation is the best strategy to defeat the pathogens and Toll like receptors (TLRs) possessing innate characteristic, mediate to destabilise the infection developments (Malik et al., 2013). Recent advances in the fields diagnosis, surveillance and monitoring, immunology, developing effective vaccines, drugs and therapeutics, and adapting appropriate hygiene and biosecurity measures along with a collaborative efforts of medical and veterinary professionals need to be explored to full potential to curb the transmission and zoonotic impact of enteric viral infections (Kahn et al., 2007; Zinsstag et al., 2007; Asokan et al., 2013; Monath, 2013; Dhama et al., 2014; Dhama et al., 2015; Shanko et al., 2015).

The present review highlights few of the important enteric viruses with a focus on their zoonotic potentials as evidenced on molecular epidemiological studies, genetic diversity, phylogenetic analysis, ecology, inter-species transmission and evolutionary genetic events. These might be responsible for emergence of new variant viruses which cross the species barriers and acquire ability to cause infections in other species with a particular reference to animal viruses affecting humans and adapting to cause zoonosis.

\section{Rotaviruses}

Amongst all enteric viral infections, rotaviruses are the leading causes of mortality and losses. They were first identified in 1969 and 1973 in fecal samples of diarrheic cattle and stool extracts of diarrheic children, respectively (Bishop et al., 1973). The genus Rotavirus within the family Reoviridae comprises of eight groups (RVA, RVB..., RVH) and two tentative groups I (RVI) and J 
(RVJ) based on the inner capsid protein (VP6) (Bányai et al., 2017). Rotavirus A has been identified as one of the major causes of severe acute gastroenteritis and mortality in young children and animals. Significant variations and diversity within the rotaviruses may be due to the point mutations, re-assortment and rearrangements within the genome of double-stranded, 11 segmented RNA. Rotaviruses are generally transmitted intraspecies specifically, with a possibility of cross-species transmission (Martella et al., 2010). Rotaviruses are generally transmitted intra-species specifically, with a possibility of crossspecies transmission (Dhama et al., 2009; Li et al., 2016). Various cases have been studied worldwide as well as in India, and have been found that animal rotaviruses can infect humans (Kang et al., 2005). Comparison between genetic sequences of humans and animals rotaviruses, has disclosed a close identity. Identifying the incidents of uncommon strains at low rate and least generation of reassortants in the human population, prompting the researchers to suggest the continuous transmission of genetic sequences of rotaviruses from animals to humans at a very low level are necessary. In rural areas, animals and humans live in close vicinity, creating an easy and quick zoonotic transmission between interspecies and generation of reassortants and virus variants.

Rotavirus strains are much diversified and their epidemiology has been widely studied presenting it to be the most prevailing cause of gastroenteritis among various host species in context of Indian scenario (Basera et al., 2010; Kattoor et al., 2013; Malik et al., 2014b). Certain animal rotavirus strains have exhibited antigenic similarities to human strains, observed using RNA-RNA hybridization assays. Phylogenetic analyses of human and animal rotavirus genome reveal repeated intersections between the strains evolution, which is probably a consequence of multiple gene reassortments. The interspecies transmission and subsequent reassortments are the important mechanisms driving the diversity of rotaviruses and enabling the emergence of new pathogenic strains with altered virulence. A report of human rotavirus group A gastroenteritis in North-eastern India has documented porcine to human zoonotic transmission (Mukherjee et al., 2009). Phylogenetic analysis of human rotavirus A from Denmark showed genetic relatedness with ovine and caprine origin rotaviruses (Midgley et al., 2012). The presence of human-like Rotavirus C (RVC) in Indian pigs appears to be the first report of $\mathrm{RVC}$ in Indian swine population, which supports its subsequent zoonotic prospective (Kattoor et al., 2017). There are also reports of detection of canine origin rotavirus A from humans (Wu et al., 2012) and reassortment between feline and human rotaviruses (Martella et al., 2011). Reverse zoonoses (zooanthroponosis) has also been reported among rotaviruses from Haryana state, northern India, where two ovine samples showed higher similarity with human group A rotavirus (RVA) at the nucleotide and amino acid sequence level (Choudhary et al., 2017). The amplification of two ovine samples with human rotavirus gene-specific primers, sequence identity and phylogenetic analysis strongly suggests the zoonotic transmission of human RVA to sheep. There is ample scope to develop newer methodologies to diagnose the new viral variants and curb the infection at an early stage. In this direction, multiple antigenic synthetic peptide, a synthetic peptide aptamers is leaping to occupy a central position, to be established in the fast and reliable diagnosis of conserved sequences of phylogenetically common viruses (Joshi et al., 2013). Some sporadic cases of RVH have also been reported in pigs in USA, Brazil, China and Japan (Wakuda et al., 2011; Marthaler et al., 2014; Molinari et al., 2015). Sequence analysis of the porcine RVH from South Africa is showing relationship with humans from Asia and partial sequence identity with Bats in Cameroon.

\section{Astroviruses}

Equally important after rotavirus is Astrovirus, which belongs to the family of Astroviridae, and consists of single-stranded positive-sense RNA viruses with a star-like appearance under the electron microscope (Appleton \& Higgins, 1975). This virus family comprises of two genera, Avastroviruses, found in birds and the Mamastroviruses, found in mammals. Astroviruses have shown high genetic diversity along with affecting broad host range including humans, bovine, swine, ovine, minks, dogs, cats, mice, chicken, and turkeys (De Benedictis et al., 2011). The mammalian viruses are often associated with gastroenteritis in most mammalian species, whereas the avian strains are known to cause both intestinal and extra-intestinal diseases (Kapoor et al., 2009), although economic losses due to reduced growth rate and productivity are yet to be established. In children, infection caused with astrovirus is comparable to rotavirus infections, as the most common cause of gastroenteritis whereas in case of animals, no correlation has been established among them except turkey and mink astrovirus. Genetic variability has been described in almost all astrovirus species but bat and pig astroviruses possess the highest diversity thus serving as a potential reservoir for human infection ( $\mathrm{Vu}$ et al., 2017). Genetic analysis of ORF2 from porcine astrovirus put forward a close relationship with human astrovirus (Ulloa \& Gutierrez, 2010). Based on a phylogenetic analysis on viral polymerase ( $\mathrm{RdRp}$ ) gene it has been found that bat astroviruses may have a great zoonotic potential and needs further investigations to provide new insights into the ecology and evolution of astroviruses (Chu et al., 2010).

To confirm the zoonosis events by in-silico analysis, we analysed few porcine and human origin astrovirus strains. The phylogenetic analysis was performed among those sequences and important information was inferred based upon their clade formation (Figure 1). The analysis was done using the MEGA 6.0 software 
applying the neighbour-joining algorithm with the support of 1000 bootstrap replicates. Although, the tree constructed for astrovirus represents the porcine sequences in a single major clade, but few porcine and human strains form another clade with 100\% bootstrap support (Figure 1).

The highlighted clade shows porcine and human strains alongside each other in a single clade suggesting possible zoonotic transmission between the species.

In astroviruses a number of lineages have been described after the continuous surveillance studies conducted on human as well as pig population. The large number of variations in the astrovirus genome results in formation of different lineages in porcine and

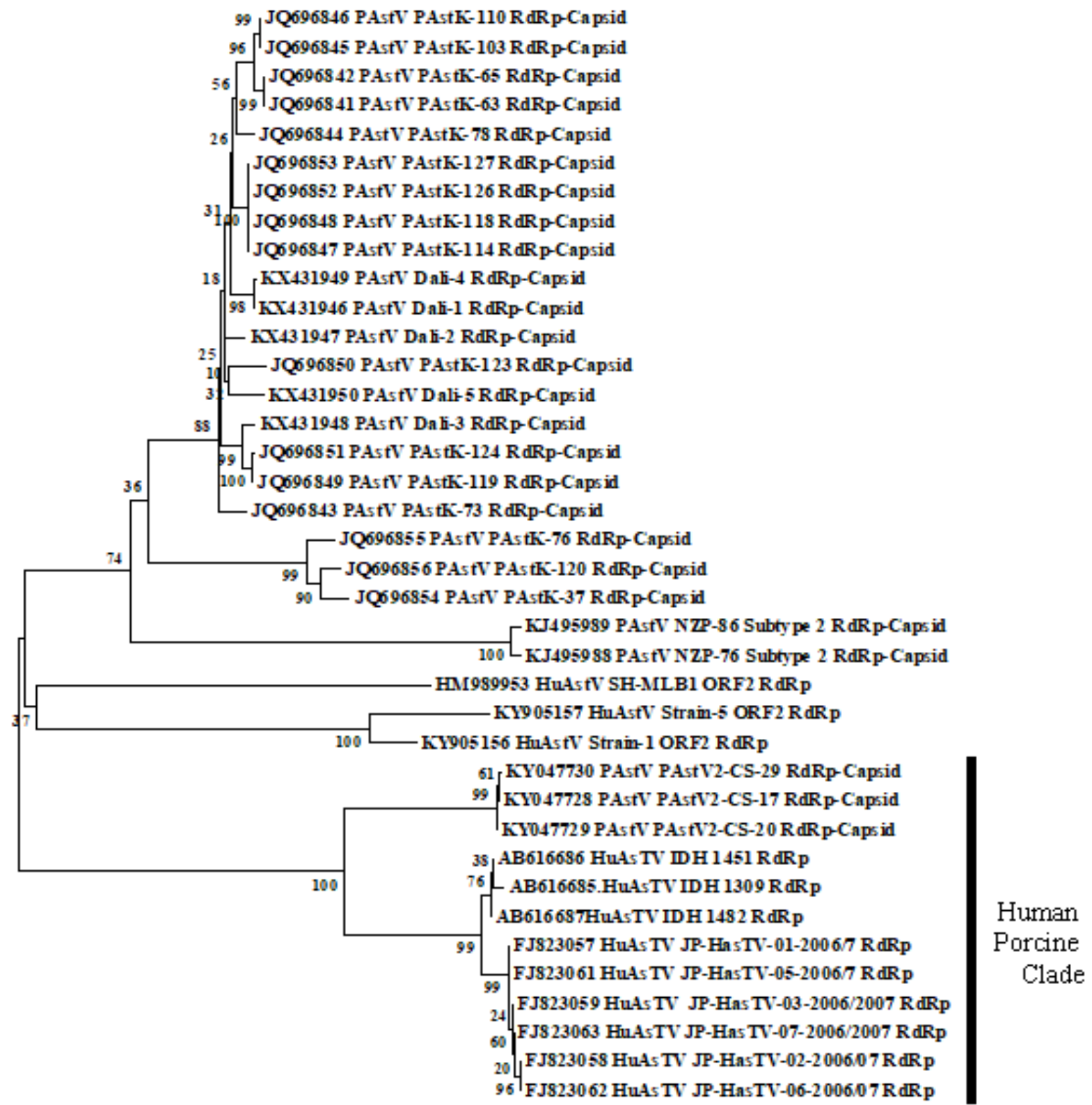

ए2

Figure 1 Phylogenetic tree of porcine and human astroviruses based on RdRp and capsid regions (The tree has been created using MEGA 6.0) 
human. The continuous variations could be responsible for the emergence of more virulent strains that may become zoonotic in nature and can cause infection to both porcine or humans and vice-versa.

\section{Caliciviruses}

During the last two decades, members of the family Caliciviridae, including Noroviruses (NoVs) and Sapoviruses (SaVs) have appeared as a cause of widespread gastroenteritis and food-borne illness. Bivalve molluscs have a high capability of filtration and, they can even concentrate virus from contaminated water. Consumption of these molluscs as raw food by humans becomes a source of the significant cause of infection with caliciviruses (Bank-Wolf et al., 2010).

Norovirus genus comprises viruses that infect a wide range of hosts including humans, pigs, cattle, and mice of all ages and in closed surroundings can lead to huge outbreaks. This wide range of hosts creates the possibility for zoonotic transmission of this viral infection (Johnson et al., 2015). Infection can be transmitted either indirectly or directly, through the food chain or animal contact. Cross-species transfer of animal virus to humans can have more drastic implications than those conventionally associated with NoV (Mattison et al., 2007). At present, amino acid sequence alignment of the major capsid protein is the base to classify the NoV strains into five genogroups (Zheng et al., 2006). Reports show existence of antibodies against animal NoVs in humans and vice-versa (Widdowson et al., 2005). The ability of human NoV to replicate and induce immunity in gnotobiotic pigs, indicates the capability of pigs to serve as reservoirs for humans (Cheetham et al., 2006). In addition, genetic similarity between human and swine NoV strains increases the chances for sub-clinically infected adult pigs to act as a reservoir and the emergence of subsequent co-infection in porcine human recombinants. Cattle can also be infected with NoV; however, this strain is less closely related to the human NoV (Menon et al., 2013). Very little information is available on immunology background and the reason for short-lived immunity of NoVs, though vaccine development has been initiated. Protection is found to be more promising in asymptomatic as well as symptomatic children but little success in adults. More than one administrative routes with multiple capsid VLPs, even an admixture of rotavirus capsid protein, offer more hope in prevention.

Sapovirus $(\mathrm{SaV})$ is a member of genus Sapporo-like viruses in the family Caliciviridae. It has the capability of infecting both humans and animals. Using electron microscopy it was first time identified in the United States in 1980 (Saif et al., 1980) and later based on its viral protein 1 (VP1) and polymerase (RdRp) are divided into seven genogroups, namely I to VII, where genogroups I, II, IV and $\mathrm{V}$ include human viruses and genogroup III, VI, and VII infects pigs, cows and mink (Jun et al., 2016). Missing sharp demarcation for host specificity and high genetic diversity indicates the co-evolution of both human and animal SaV (Reuter et al., 2010). Sapovirus is among the few culturable enteric caliciviruses. Recently, amino acid substitution in the VP1 capsid region has been found to be the base adopted by $\mathrm{SaV}$ for the culture in the porcine Cowden strain, boosting the desire to culture other non-culturable viruses.

\section{Hepatitis viruses}

Hepatitis E virus (HEV) is another significant enteric zoonotic viral disease. Few animal hosts' viz. swine, wild boars, and deer have been identified as the reservoirs of this disease. It has acquired the status of leading cause of hepatitis in human's worldwide (Kamar et al., 2012; Mirazo et al., 2014). In general, HEV associated conditions are self-limiting and recovery comes within 3 months from appearance of symptoms. However, estimates submits involvement of nearly 20 million cases every year, where more than 3 million cases exhibit symptoms and approximately 50,000 succumb to deaths globally (Kamar et al., 2012).

It is a single-stranded, positive-sense RNA virus in the Hepeviridae family. The first existence of HEV was suggested during an outbreak of hepatitis in Kashmir Valley in 1978 (Khuroo, 1980). HEV, so far belong to the Orthohepevirus genus that is divided into four species: Orthohepevirus A, B, C and D and, among these main genotypes belong to the Orthohepevirus $\mathrm{A}$ (HEV-1 to 4). HEV-1 and HEV-2 infect only humans and are associated with large waterborne epidemics, whereas HEV-3 and HEV-4 infecting humans and other animals, causing endemic cases of hepatitis E (Doceul et al., 2016; Tedder et al., 2017). The HEV GT1 shows higher intensity and fatality in immunocompromised patients which may reach to $25 \%$ and in endemic regions may affect more than $50 \%$ cases with acute viral hepatitis (Kamar et al., 2012). Usually, HEV transmission occurs from contaminated water but at a times few cases appears with animal based transmission also. In humans, the source of infection is associated to contact with infected animals or to consumption of raw or undercooked meat (Takahashi et al., 2004; Meng, 2011; Park et al., 2016). A large scale survey in Vietnamese pigs and human population evidenced zoonotic transmission of HEV genotypes (GT), particularly GT3 and 4 (Berto et al., 2017). Overall, the HEVs zoonotic spread has been well documented globally and thus HEV GT3 and 4 are of major concern to be tackled.

\section{Picobirnaviruses}

Among most recently identified virus family, the Picobirnaviridae, picobirnaviruses (PBVs) are the small, non- 
enveloped, bi-segmented double-stranded RNA genomic viruses affecting a wide range of vertebrate hosts (Malik et al., 2014a). PBVs have been frequently detected as a co-infection along with other diarrhoeal agents and in some cases, prolonged shedding has been noticed (Ganesh et al., 2012b). In pigs and other animal hosts, matching patterns of PBV infection have also been detected (Geng et al., 2011). The increasing amount of PBV phylogenetic data based on segment 2 (RdRp) gathered from molecular epidemiological studies has evidenced a great genetic diversity of PBVs in various hosts and environmental samples. There are two genogroup (I and II) circulating throughout the world. Evidence are available on high genetic relatedness between human and porcine PBVs, human and equine PBVs and, human and rodents PBVs, suggesting extant crossing points in the ecology and evolution of heterologous PBV strains (Malik et al., 2014b; Kattoor et al., 2016). Very recently, Picobirnavirus has also been detected in dogs and bats, Vervet monkeys, wolves (ConceicaoNeto et al., 2016) on the basis of complete genome sequence 2.

To confirm the zoonosis events by in-silico analysis we analysed few porcine and human origin PBV strains isolated world over (Figure 2). The phylogenetic analysis was performed among those

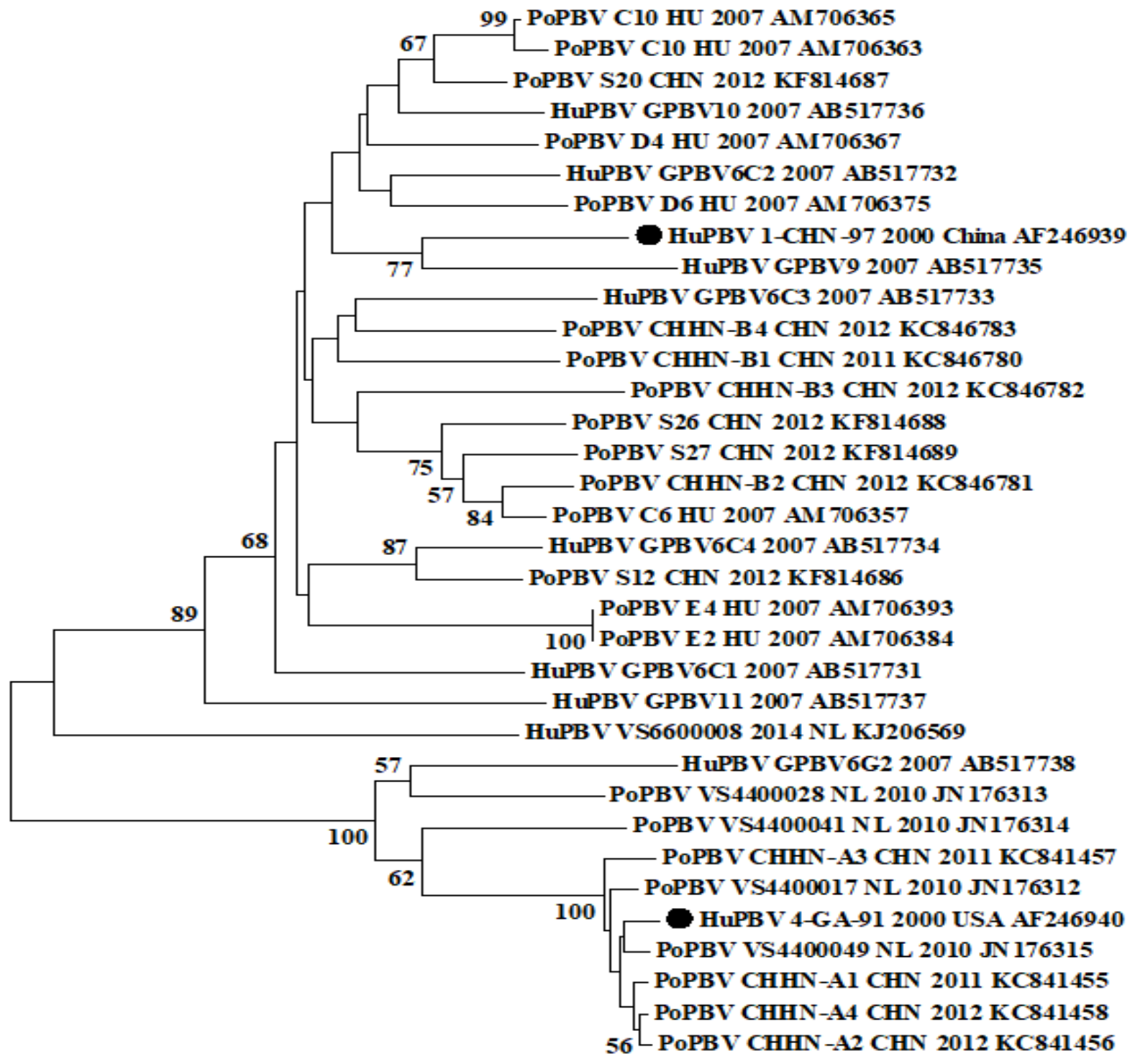

$\longmapsto 005$

Figure 2 Phylogenetic tree of porcine and human picobirnavirus (PBV) based on RdRp gene (The tree has been created using MEGA 6.0)

Journal of Experimental Biology and Agriculture Science http://www.jebas.org 
sequences and inferred some important information based upon their clade formation. The analysis was done using the MEGA 6.0 software applying the neighbour-joining algorithm with the support of 1000 bootstrap replicates. Huge diversity was observed among the PBV sequences with both porcine and human origin strains dispersed all over the phylogeny (Figure 2).

Strains represented by the black dots are reference PBV strains. The tree shows different human and porcine strains in different clades pointing towards continuous zoonoses events going on between both species.

Being a segmented virus the chances of reassortment among PBVs increases as their bipartite nature supports the events leading to formation of new variants. Therefore, the probabilities regarding the emergence of zoonotic strains are always likely to occur. Hence, frequent zoonosis events from porcine to human in PBVs are often reported and pigs are predicted to harbour these infectious strains which could become a putative threat to human health.

\section{Role of Wildlife in Zoonoses}

Wildlife is considered as reservoir for nearly $75 \%$ of zoonotic infections. Rabies and West Nile virus were among the most common examples, whose history is well known (Marr \& Calisher, 2003). Recent emerging diseases like SARS, AIDS, avian influenza have been tracked in wildlife animals and have travelled to humans. This is just because of the invasions made by humans to their habitats and claims they imbue. These transmissions are either direct or through the vectors (insects, rodents, etc.) from one species to another (Bengis et al., 2004). It can also be through the shedding of viruses in animal discharges like faeces, nasal, respiratory discharges. Birds carry some of the pathogens to a long distance through aerial routes while their seasonal migrations. Thus, their surveillance becomes necessity to check the spread of viruses and to create a clear demarcation for preventing the further extension deep in the line. Now close relations with wild animals is also a threat for the transfer of few viruses from the authorized serving personnel's to the main stream society. The changes in the agro-climatic conditions, migrations and anthropogenic factors are also helping in the evolution of new viruses at a much rapid pace now. Efforts to cut the direct transmission may help to reduce the economic burden.

\section{Conclusion and future prospects}

Enteric viral infections are the well-recognized cause of substantial losses and health problems both in developed and developing countries. With the advent of next-generation sequencing methodology and other state-of-art tools, several uncommon viruses have been detected in the patients suffering from gastroenteritis. Constantly increasing proofs are ascertaining that direct transmission of virus or reassortment among one or several genes may be the reason and asserting the capability of transmission of animal enteric viruses to infect humans These viruses may affect people of all age groups, often transmitted by fecal-contaminated food or water, and thus controlling these pathogens through enhancing public health hygienic measures and adapting strict biosecurity principles is of utmost importance. For the reassortment of the genes, mixed infections is the basic necessity. To track the co-circulating viruses and to study the insight for better understanding and establishing the co-relation, surveillance of human as well as animal virus strains is a critical step. With this, the strategic and strict control of the animal movement within the country and across the international border is also needed. Investigations at the global level will provide the important information regarding the diversity, prevalence, genetic heterogenicity, pathogenic potentiality, interspecies transmission ability and epidemiology of these zoonotic viruses. For the indepth understanding and to curb such prevailing, emerging/ or reemerging enteric viral infections we have to gather urgently sound scientific information on these pathogens including their reservoir hosts, immunopathology, genetic diversity and the development of modern diagnostic tools as well as strengthening the recent advances for designing and developing effective drugs and therapeutic regimens. There is necessity to implement the OneHealth approaches while dealing with the zoonotic infectious. Implementation of public health control measures would be crucial in reducing disease affliction and developing preparedness well in advance to mitigate the losses associated with disease epidemics. Therefore, this is the apt time to establish trust worthy relationship between the animal health and public health services. A comprehensive approach will also include regular inclusion of wildlife including linked ecosystems. Lately, the concept of "One Health," and its usefulness has been understood thoroughly, the only point remains is its implementation.

\section{Acknowledgement}

All the authors acknowledge and thank their respective Institutes and Universities.

\section{Funding}

This compilation is a review article written, analysed and designed by its authors and required no substantial funding to be stated.

\section{Conflicts of interest}

All authors declare that there exist no commercial or financial relationships that could in any way lead to a potential conflict of interest. 


\section{References}

Appleton H, Higgins PG (1975) Letter: Viruses and gastroenteritis in infants. Lancet 1: 1297-1297.

Asokan GV, Kasimanickam RK, Asokan V (2013) Surveillance, response systems, and evidence updates on emerging zoonoses: the role of one health. Infection Ecology and Epidemiology 3: 10.3402/iee.v3i0.21386.

Bank-Wolf BR, König M, Thiel HJ (2010) Zoonotic aspects of infections with noroviruses and sapoviruses. Veterinary Microbiology 140: 204-212.

Bányai K, Kemenesi G, Budinski I, Földes F, Zana B, Marton S, Varga-Kugler R, Oldal M, Kurucz K, Jakab F (2017) Candidate new rotavirus species in Schreiber's bats, Serbia. Infection, Genetics and Evolution 48: 19-26.

Basera SS, Singh R, Vaid N, Sharma K, Chakraborti S, Malik YS (2010) Detection of rotavirus infection in bovine calves by RNAPAGE and RT-PCR. Indian Journal of Virology 21: 144-147.

Bengis RG, Leighton FA, Fischer JR, Artois M, Morner T, Tate CM (2004) The role of wildlife in emerging and re-emerging zoonoses. Revue scientifique et technique-Office International des Epizooties 23: 497-512.

Berto A, Pham HA, Thao TTN, Vy NHT, Caddy SL, Hiraide R, Tue NT, Goodfellow I, Carrique-Mas JJ, Thwaites GE, Baker S, Boni MF (2017) Hepatitis E in southern Vietnam: Seroepidemiology in humans and molecular epidemiology in pigs. Zoonoses and Public Health 2017 Jun 9. doi: 10.1111/zph.12364. [Epub ahead of print]

Bishop RF, Davidson GP, Holmes IK, Ruck BJ (1973) Virus particles in epithelial cells of duodenal mucosa from children with acute nonbacterial gastroenteritis. Lancet 2: 1281-1283.

Cheetham S, Souza M, Meulia T, Grimes S, Han MG, Saif LJ (2006) Pathogenesis of a genogroup II human norovirus in gnotobiotic pigs. Journal of Virology 80: 10372-10381.

Choudhary P, Minakshi P, Ranjan K, Basanti B (2017) Zooanthroponotic transmission of rotavirus in Haryana State of Northern India. Acta Virologica 61: 77-85.

Chu DKW, Chin AWH, Smith GJ, Chan KH, Guan Y, Peiris JM, Poon LL (2010) Detection of novel astroviruses in urban brown rats and previously known astroviruses in humans. Journal of General Virology 91: 2457-2462.

Conceicao-Neto N, Mesquita JR, Zeller M, Claude Kwe Yinda CK, lvares FA, Roque S, Francisco Petrucci-Fonseca, Godinho R,
Heylen E, Ranst MV, Matthijnssens J (2016) Reassortment among picobirnaviruses found in wolves. Archives of Virology 161: 2859-2862.

De Benedictis P, Schultz-Cherry S, Burnham A, Cattoli G (2011) Astrovirus infections in humans and animals-molecular biology, genetic diversity, and interspecies transmissions. Infection, Genetics and Evolution 11: 1529-1544.

Dhama K, Chakraborty S, Tiwari R, Verma AK, Saminathan M, Malik YS, Nikousefat Z, Javdani M, Khan RU (2014) A concept paper on novel technologies boosting production and safeguarding health of humans and animals. Research Opinions in Animal and Veterinary Sciences 4: 353-370.

Dhama K, Chauhan RS, Mahendran M, Malik SVS (2009) Rotavirus diarrhea in bovines and other domestic animals. Veterinary Research Communications 33: 1-23.

Dhama K, Karthik K, Chakraborty S, Tiwari R, Kapoor S (2013b) Wildlife: a hidden warehouse of zoonosis - a review. International Journal of Current Research5: 1866-1879.

Dhama K, Saminathan M, Jacob SS, Singh M, Karthik K, Amarpal, Tiwari R, Sunkara LT, Malik YS, Singh RK (2015) Effect of immunomodulation and immunomodulatory agents on health with some bioactive principles, modes of action and potent biomedical applications. International Journal of Pharmacology 11: 253-290.

Dhama K, Tiwari R, Chakraborty S, Kumar A, Karikalan M, Singh R, Rai RB (2013a) Global warming and emerging infectious diseases of animals and humans: current scenario, challenges, solutions and future perspectives - a review. International Journal of Current Research 5: 1942-1958.

Doceul V, Bagdassarian E, Demange A, Pavio N (2016) Zoonotic Hepatitis E Virus: Classification, Animal Reservoirs and Transmission Routes. Viruses 8: 270.

Ganesh B, Bányai K, Kanungo K, Sur D, Malik YS, Kobayashi N (2012a) Detection and molecular characterization of porcine picobirnavirus in feces of domestic pigs from Kolkata, India. Indian Journal of Virology 23: 387-391.

Ganesh B, Bányai K, Martella V, Jakab F, Masachessi G, Kobayashi N (2012b) Picobirnavirus infections: viral persistence and zoonotic potential. Reviews in Medical Virology 22: 245-256.

Geng J, Wang L, Wang X, Fu H, Bu Q, Liu P, Zhu Y, Wang M, Sui Y, Zhuang H (2011) Potential risk of zoonotic transmission from young swine to human: seroepidemiological and genetic 
characterization of hepatitis $\mathrm{E}$ virus in human and various animals in Beijing, China. Journal of Viral Hepatitis 18: e583-590.

Greger M (2007) The Human/Animal Interface: Emergence and Resurgence of Zoonotic Infectious Diseases. Critical Reviews in Microbiology 33: 243-299.

Johnson C, Hitchens PL, Smiley Evans T, Goldstein T, Thomas K, Clements A, Joly DO, Wolfe ND, Daszak P, Karesh WB, Mazet JK (2015) Spillover and pandemic properties of zoonotic viruses with high host plasticity. Scientific Reports 5: 14830.

Joshi VG, Dighe VD, Thakuria D, Malik YS, Kumar S (2013) Multiple antigenic peptide (MAP): a synthetic peptide dendrimer for diagnostic, antiviral and vaccine strategies for emerging and re-emerging viral diseases. Indian Journal of Virology 24: 312320 .

Jun Q, Lulu T, Qingling M, Xingxing Z, Haiting L, Shasha G, Zibing C, Xuepeng C, Jinsheng Z, Zaichao Z, Kuojun C, Chuangfu C (2016) Serological and molecular investigation of porcine sapovirus infection in piglets in Xinjiang, China. Tropical Animal Health and Production 48: 863-869.

Kahn LH, Kaplan B, Steele JH (2007) Confronting zoonoses through closer collaboration between medicine and veterinary medicine (as ‘one medicine'). Veterinaria Italiana 43: 5-19.

Kamar N, Bendall R, Legrand-Abravanel F, Xia N-S, Ijaz S, Izopet J, Dalton Harry R (2012) Hepatitis E. Lancet 379: $2477-$ 2488.

Kang G, Kelkar SD, Chitambar SD, Ray P, Naik T (2005) Epidemiological profile of rotaviral infection in India: challenges for the 21st century. Journal of Infectious Diseases 192: S120-S126)

Kapoor A, Li L, Victoria J, Oderinde B, Mason C, Pandey P, Zaidi SZ, Delwart E (2009) Multiple novel astrovirus species in human stool. Journal of General Virology 90: 2965-2972.

Kattoor JJ, Malik YS, Sharma K, Kumar N, Batra M, Jindal N, Yadav AS (2013) Molecular evidence of group D rotavirus in commercial broiler chicks in India. Avian Biology Research 6: 313-316.

Kattoor JJ, Saurabh S, Malik YS, Sircar S, Dhama K, Ghosh S, Bányai K, Kobayashi N, Singh RK (2017) Unexpected detection of porcine rotavirus $\mathrm{C}$ strains carrying human origin VP6 gene. Veterinary Quarterly 37: 252-261.

Kattoor JJ, Sircar S, Saurab S, Subramaniyan S, Dhama K, Malik YS (2016) Picobirnavirus: A putative emerging threat to humans and animals. Advances in Animal and Veterinary Sciences 4: $327-$ 331.

Khuroo MS (1980) Study of an epidemic of non-A, non-B hepatitis. Possibility of another human hepatitis virus distinct from post-transfusion non-A, non-B type. American Journal of Medicine 68: 818-824.

Klous G, Huss A, Heederik DJJ, Coutinho RA (2016) Human livestock contacts and their relationship to transmission of zoonotic pathogens, a systematic review of literature. One Health 2: $65-76$

Kusumakar AL, Malik YS, Prasad G (2010) Genomic diversity among group A rotaviruses from diarrheic children, piglets, buffalo and cow calves of Madhya Pradesh. Indian Journal of Microbiology 50: 83-88.

Li K, Lin XD, Huang KY, Zhang B, Shi M, Guo WP, Wang MR, Wang W, Xing JG, Li MH, Hong WS, Holmes EC, Zhang YZ (2016) Identification of novel and diverse rotaviruses in rodents and insectivores, and evidence of cross-species transmission into humans. Virology 494: 168-177.

Malik YS, Kuldeep S, Jeena LM, Naveen K, Subhankar S, Rajak KK, Dhama K (2013) Toll-like receptors: the innate immune receptors with ingenious anti-viral paradigm. South Asian Journal of Experimental Biology 3: 207-213.

Malik YS, Kumar N, Sharma K, Dhama K, Shabbir MZ, Ganesh B, Kobayashi N, Banyai K (2014a) Epidemiology, phylogeny, and evolution of emerging enteric Picobirnaviruses of animal origin and their relationship to human strains. Biomed Research International 780752.

Malik YS, Kumar N, Sharma K, Sircar S, Dhama K, Bora DP, Dutta TK, Prasad M, Tiwari AK (2014b) Rotavirus diarrhea in piglets: A review on epidemiology, genetic diversity and zoonotic risks. Indian Journal of Animal Sciences 84: 1035-1042.

Malik YS, Matthijnssens (2014) Enteric viral infection in human and animal. Virus Diseases 25: 145-146.

Marr JS, Calisher CH (2003) Alexander the Great and West Nile virus encephalitis-Historical Review. Emerging Infectious Diseases $9: 1599-1603$.

Martella V, Bányai K, Matthijnssens J, Buonavoglia C, Ciarlet M (2010) Zoonotic aspects of rotaviruses. Veterinary Microbiology 140: 246-255.

Martella V, Potgieter AC, Lorusso E, De Grazia S, Giammanco GM, Matthijnssens J, Bányai K, Ciarlet M, Lavazza A, Decaro N, Buonavoglia C (2011) A feline rotavirus G3P[9] carries traces of 
multiple reassortment events and resembles rare human G3P[9] rotaviruses. Journal of General Virology 92: 1214-1221.

Marthaler D, Rossow K, Culhane M, Goyal S, Collins J, Matthijnssens J, Nelson M, Ciarlet M (2014) Widespread rotavirus $\mathrm{H}$ in commercially raised pigs, United States. Emerging Infectious Diseases 20 : 1203.

Mattison K, Shukla A, Cook A, Pollari F, Friendship R, Kelton D, Bidawid S, Farber JM (2007) Human Noroviruses in Swine and Cattle. Emerging Infectious Diseases 13: 1184-1188.

Meng XJ (2011) From barnyard to food table: the omnipresence of hepatitis E virus and risk for zoonotic infection and food safety. Virus Research 161: 23-30.

Menon VK, George S, Shanti AA, Saravanabavan A, Samuel P, Ramani S, Estes MK, Kang G (2013) Exposure to human and bovine noroviruses in a birth cohort in southern India from 2002 to 2006. Journal of Clinical Microbiology 51: 2391-2395.

Messenger AM, Barnes AN, Gray GC (2014) Reverse Zoonotic Disease Transmission (Zooanthroponosis): A Systematic Review of Seldom-Documented Human Biological Threats to Animals. PLoS ONE 9: e89055.

Midgley SE, Hjulsager CK, Larsen LE, Falkenhorst G, Böttiger B (2012) Suspected zoonotic transmission of rotavirus group A in Danish adults. Epidemiology and Infection 140: 1013-1017.

Mirazo S, Ramos N, Mainardi V, Gerona S, Arbiza J (2014) Transmission, diagnosis, and management of hepatitis E: an update. Hepatic Medicine 6: 45-59.

Molinari BL, Alfieri AF, Alfieri AA (2015) Genetic variability of VP6, VP7, VP4, and NSP4 genes of porcine rotavirus group $\mathrm{H}$ detected in Brazil. Virus research 197: 48-53.

Monath TP (2013) Vaccines against diseases transmitted from animals to humans: a one health paradigm. Vaccine 31:53215338.

Mukherjee A, Dutta D, Ghosh S, Bagchi P, Chattopadhyay S, Nagashima S, Kobayashi N, Dutta P, Krishnan T, Naik TN, Chawla-Sarkar M (2009) Full genomic analysis of a human group A rotavirus G9P[6] strain from Eastern India provides evidence for porcine-to-human interspecies transmission. Archives of Virology 154:733-746.

Munjal A, Khandia R, Dhama K, Sachan S, Karthik K, Tiwari R, Malik YS, Kumar D, Singh RK, Iqbal HMN, Joshi S (2017) Advances in developing therapies to combat Zika virus: Current knowledge and future perspectives. Frontiers in Microbiology 8: 1469.
Parashar UD, Burton A, Lanata C, Boschi-Pinto C, Shibuya K, Steele D, Birmingham M, Glass RI (2009) Global mortality associated with rotavirus disease among children in 2004. Journal of Infectious Diseases 200(S1):S9-S15.

Park WJ, Park BJ, Ahn HS, Lee JB, Park SY, Song CS, Lee SW, Yoo HS, Choi IS (2016) Hepatitis E virus as an emerging zoonotic pathogen. Journal of Veterinary Science 17: 1-11.

Patnayak DP, Prasad M, Malik YS, Ramakrishnan MA, Goyal SM (2008) Efficacy of disinfectants and hand sanitizers against avian respiratory viruses. Avian Diseases 52: 199-202.

Prasad G, Malik YS, Pandey R (2005) G and P genotyping of bovine group A rotaviruses in faecal samples of diarrhoeic calves by DIG-labelled probes. Indian Journal of Biotechnology 4: 9399.

Reuter G, Zimsek-Mijovski J, Poljsak-Prijatelj M, Di Bartolo I, Ruggeri FM, Kantala T, Maunula L, Kiss I, Kecskeméti S, Halaihel N, Buesa J, Johnsen C, Hjulsager CK, Larsen LE, Koopmans M, Böttiger B (2010) Incidence, diversity, and molecular epidemiology of sapoviruses in swine across Europe. Journal of Clinical Microbiology 48: 363-368.

Saif LJ, Bohl EH, Theil KW, Cross RF, House JA (1980) Rotavirus-like, calicivirus-like, and $23-\mathrm{nm}$ virus-like particles associated with diarrhea in young pigs. Journal of Clinical Microbiology 12: 105-111.

Shanko K, Kemal J, Kenea D (2015) A Review on Confronting Zoonoses: The Role of Veterinarian and Physician. Journal of Veterinary Science and Technology 6: 221.

Singh RK, Dhama K, Malik YS, Ramakrishnan MA, Karthik K, Tiwari R, Khandia R, Munjal A, Saminathan M, Sachan S, Desingu PA, Kattoor JJ, Iqbal HMN, Joshi SK (2017) Ebola Virus - Epidemiology, Diagnosis and Control: Threat to Humans, Lessons Learnt and Preparedness Plans- an Update on its 40 Year's Journey. Veterinary Quarterly 37: 98-135.

Sircar S, Saurabh S, Kattoor JJ, Deol P, Dhama K, Khurana SK, Malik YS (2016) Evolving views on enteric viral infections of equines: An appraisal of key pathogens Journal of Experimental Biology and Agriculture Science 4(Spl-4-EHIDZ): S182-195.

Takahashi K, Kitajima N, Abe N, Mishiro S (2004) Complete or near-complete nucleotide sequences of hepatitis $\mathrm{E}$ virus genome recovered from a wild boar, a deer, and four patients who ate the deer. Virology 330: 501-505.

Tate JE, Burton AH, Boschi-Pinto C, Steele AD, Duque J, Parashar UD (2008) Estimate of worldwide rotavirus-associated 
mortality in children younger than 5 years before the introduction of universal rotavirus vaccination programmes: a systematic review and meta-analysis. Lancet Infectious Diseases 12 :136141.

Tedder RS, Ijaz S, Kitchen A, Ushiro-Lumb I, Tettmar KI, Hewitt P, Andrews N (2017) Hepatitis E risks: Pigs or blood-that is the question. Transfusion 57: 267-272

Tian HY, Tong SL (2017) Recent advance in eco-epidemiological model: zoonotic disease transmission and environmental factors. Zhonghua yu fang yi xue za zhi [Chinese Journal of Preventive Medicine]51: 8 .

Tomley FM, Shirley MW (2009) Livestock infectious diseases and zoonoses. Philosophical Transactions of the Royal Society B: Biological Sciences 364: 2637-2642.

Ulloa JC, Gutierrez MF (2010) Genomic analysis of two ORF2 segments of new porcine astrovirus isolates and their close relationship with human astroviruses. Canadian Journal of Microbiology 56: 569-577.

GBD 2015 Disease and Injury Incidence and Prevalence Collaborators (2016) Global, regional, and national incidence, prevalence, and years lived with disability for 310 diseases and injuries, 1990-2015: a systematic analysis for the Global Burden of Disease Study 2015. Lancet 388: 1545-1602.

Vu DL, Bosch A, Pintó RM, Guix S (2017) Epidemiology of
Classic and Novel Human Astrovirus: Gastroenteritis and Beyond. Viruses 9: 33.

Wakuda M, Ide T, Sasaki J, Komoto S, Ishii J, Sanekata T, Taniguchi K (2011) Porcine rotavirus closely related to novel group of human rotaviruses. Emerging Infectious Diseases 17(8): 1491.

Wang LF, Crameri G (2014) Emerging zoonotic viral diseases. Revue Scientifique et Technique (International Office of Epizootics) 33: 569-581

Widdowson MA, Rockx B, Schepp R, van der Poel WHM, Vinje J, van Duynhoven YT, Koopmans MP (2005) Detection of serum antibodies to bovine norovirus in veterinarians and the general population in the Netherlands. Journal of Medical Virology 76: 119-128.

Wu FT, Bányai K, Lin JS, Wu HS, Hsiung CA, Huang YC, Hwang KP, Jiang B, Gentsch JR (2012) Putative canine origin of rotavirus strain detected in a child with diarrhea, Taiwan. VectorBorne and Zoonotic Diseases 12: 170-173.

Zheng DP, Ando T, Fankhauser RL, Beard RS, Glass RI, Monroe SS (2006) Norovirus classification and proposed strain nomenclature. Virology 346: 312-323.

Zinsstag J, Schelling E, Roth F, Bonfoh B, De Savigny D, Tanner M (2007) Human benefits of animal interventions for zoonosis control. Emerging Infectious Diseases 13: 527-531. 